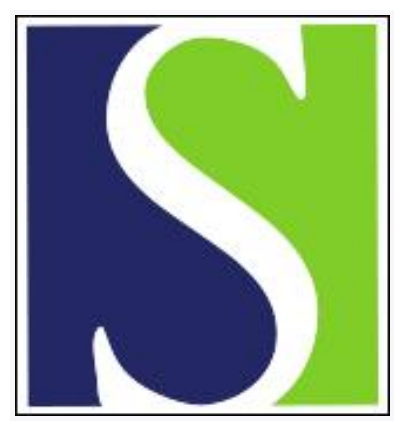

Scand J Work Environ Health 2010;36(6):449-457

https://doi.org/10.5271/sjweh.3081

Published online: 20 Aug 2010, Issue date: Nov 2010

Discrepancy between objective and subjective measures of job stress and sickness absence

by Rehkopf DH, Kuper H, Marmot MG

Affiliation: University of California San Francisco, San Francisco CA 94107.drehkopf@epi.ucsf.edu

Refers to the following text of the Journal: 2001;27(1):70-75

Key terms: conflicting demands; decision latitude; demand-control; job discretion; job strain; job stress; measurement method; objective measure; sickness absence; strain; stress; subjective measure; work pace

This article in PubMed: www.ncbi.nlm.nih.gov/pubmed/20725704

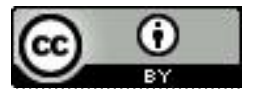




\title{
Discrepancy between objective and subjective measures of job stress and sickness absence
}

by David H Rehkopf, ScD, MPH, Hannah Kuper, ScD, ${ }^{1}$ Michael G Marmot, PhD, MD ${ }^{3}$

\begin{abstract}
Rehkopf DH, Kuper H, Marmot MG. Discrepancy between objective and subjective measures of job stress and sickness absence. Scand J Work Environ Health. 2010;36(6):449-457.

Objectives The aim of this study was to examine the association of the discrepancy between externally and self-assessed measures of work environment with long- and short-term sickness absence.

Methods The study population included 6997 middle-aged men and women from the Whitehall II cohort, whose work characteristics were examined at baseline (1985-1988) through both an external evaluation and self-report, with a follow-up of up to 13 years of sickness absence reporting from administrative records. The primary exposure of interest was the discrepancy between measures of work stress for fast job pace, conflicting demands, and decision latitude.
\end{abstract}

Results In mutually adjusted models, external measures of job characteristics were more strongly associated with higher rates of sickness absence compared with self-assessed measures, for both lower frequency of fast work pace and lower conflicting demands (ie "passive" levels). Individuals who self-reported higher frequencies of fast work pace and conflicting demands than were reported through external assessment had higher rates of short-term sickness absence [incident rate ratios (IRR) of 1.13 [95\% confidence interval (95\% CI) $1.11-1.15$ ] and IRR 1.14 (95\% CI 1.11-1.16), respectively]. There was no difference in rates of sickness absence found for decision latitude [IRR 1.02 (95\% CI 1.00-1.04)].

Conclusions Our findings demonstrate that the discrepancy between externally and self-assessed job demand measures have additional predictive power beyond each individual measure of job structure, which may be related to the extent of cognitive and emotional processing of assessment questions as compared to decision latitude measures.

Key terms conflicting demand; decision latitude; demand-control; job discretion; job strain; measurement method; strain; work pace.

Job structure may relate to health, either through the association with deleterious increases in stress or through the beneficial promotion of an active work environment $(1,2)$. The association of measures of stress in the workplace (including conflicting demands, work pace, and decision latitude) with health outcomes has been demonstrated in a number of studies (3-10), but there are several non-causal mechanisms that may explain these associations including confounding by negative affect, health behaviors, or social class in addition to reverse causation where individuals with underlying poor health may rate their jobs as more stressful (11).
The magnitude of the association between work stress and health has varied depending on the method used to measure work characteristics. In reviewing the evidence for the impact of work characteristics on health, several authors have called for a more careful consideration of measurement methods. Job characteristics have been evaluated by both self-report by subject and evaluation external to subject. The selfreport method may be biased by the personal lens through which the individual views the world $(12,13)$. If unhealthy workers perceive their environments as more stressful than they appear to be, objectively this

1 Department of Epidemiology \& Biostatistics, University of California, San Francisco, USA.

2 Non-Communicable Disease Epidemiology Unit, London School of Hygiene \& Tropical Medicine, London, UK.

3 International Centre for Health and Society, Department of Epidemiology and Public Health, University College London, London, UK.

Correspondence to: David H Rehkopf, University of California San Francisco, 185 Berry Street, Lobby 6, Suite 6600, San Francisco CA 94107. [E-mail address: drehkopf@epi.ucsf.edu] 
would lead to confounded associations between works stress measures and health outcomes. Evaluation external to the subject usually involves a report either by a direct observer of that person's work environment or by someone familiar with the particular job. Thus external evaluation will not be impacted by attributes of the individual performing a job, although they may arguably have less sensitivity to subtle variations in exposures to which individuals are subjected (12).

There has been a paucity of research into the relationships between these different methods of assessment (14, 15), while at the same time it has been acknowledged that objective and subjective measures have unique and often complementary strengths and limitations $(11,16)$. In part to guide structural interventions in the workplace, there is an interest in evaluating the aspects of job stress that are associated specifically with a job, rather than with the workers who occupy that particular job. The concept of "shared job strain" was initially evaluated by estimating a latent variable to determine aspects of job stress that were shared by different types of individuals who occupied the same type of job (17). Alternatively, the discrepancy between self-report and objectively measured variables can be interpreted as characteristics perceived by individuals beyond what objectively exists in the structure of the job. This may be particularly salient for items that require a greater degree of cognitive and emotional processing, which is likely to be greater for the appraisal of stressors as compared to resources (11). Thus, the discrepancy between subjective and objective measures may itself be associated with sickness absence because the discrepancy may relate to individual characteristics associated with risk for sickness absences that are not caused by job structure. In contrast, there may be little additional predictive power of subjective (self-report) descriptions of a job environment beyond objective (externally assessed) job environment measures because the differences in perception of the work structure may be random measurement errors and not related to health.

In this study, we aim to investigate the association between self-report and externally-assessed work characteristics and rates of short- and long-term sickness absence using extended follow-up to earlier reports from the Whitehall II study $(8,9)$. We aim to investigate (i) whether each measure predicts rates of sickness absence independently and (ii) if the discrepancies between selfreport and externally assessed measures of the work environment predict future rates of sickness absence. A substantial difference in rates of sickness absence by discrepancy implies that objective and subjective measures of the work stress environment are subject to measurement error. This measurement error is most likely due to either (i) differences in subject perceptions that are related to sickness absence or (ii) accuracy of the external measurement of the work environment. We hypothesize that due to greater evidence from the literature about the direction of the bias through which an individual perceives their environment, the most likely interpretation of positive findings is that negative perceptions of the work environment also lead to increased sickness absence.

\section{Methods}

\section{Study population}

The Whitehall II study is a cohort of civil servants that was established between 1985-1988 (phase 1) (18). All non-industrial civil servants aged $35-55$ years working in the London offices of 20 departments were sent an introductory letter and screening questionnaire and were offered a screening examination for cardiovascular disease. The overall response rate was $73 \%$ ( $74 \%$ for men, $71 \%$ for women). Of the 10308 civil servants participating in phase one, 7830 continued to be enrolled by phase 5 (1997-2000). Because not all jobs were evaluated by external evaluators, the final analytic sample of individuals was $\mathrm{N}=6997$ for work pace and decision latitude and $\mathrm{N}=6400$ for conflicting demands (respectively $89 \%$ and $82 \%$ of individuals remaining in the cohort at phase 5). Mean follow-up time was 7.5 years.

\section{Sickness absence data}

Computerized sickness absence records to the end of December 1998 were obtained from the civil service pay centers. For spells of $\leq 7$ calendar days (short spells), reason for absence was based on self-report. For spells of $>7$ calendar days (long spells), a medical certificate was required.

The total number of short spells was 43796 for men and 26893 for women (an average of 1.2 and 1.8 short spells per person-year respectively). The total number of long spells was 4607 for men and 4213 for women (an average of 0.12 and 0.28 long spells per person-year, respectively).

\section{Work characteristics}

We focused on conflicting demands, work pace, and decision latitude as measures of the work environment as these factors were measured through both self-report and external assessment in phase 1 (1985-1988). First, each participant provided self-report work characteristics in the baseline questionnaire. The following questions were used to measure (i) conflicting demands, (ii) work pace and (iii) decision latitude: (i) "Do different groups at work demand things from you that you think 
are hard to combine?" (ii) "Do you have to work fast?" (iii) "I have a good deal of say in decisions about work". Possible responses were: "often", "sometimes", "seldom" and "almost never".

The second distinct measurement of the work environment was external assessments of each job by individuals familiar with the tasks, responsibilities, and pressures of each specific job. In 18 of the 20 departments that were part of the Whitehall II cohort, 140 personnel managers assessed different items for each job title in phase 1 (1985-1988). The three questions used for this analysis (each rated on a scale of 1-12) were (i) "How often do different groups at work demand things which are difficult to combine?" (ii) "How often does the job involve working very fast?" and (iii) "How often does the job permit complete discretion and independence in determining how, and when, the work is to be done?" Personnel managers were well suited to this task since they recruit and supervise staff in a number of jobs in different grades and thus are familiar with a relatively wide range of work environments. To validate the objective assessment, a random sample of 710 jobs was rated independently by two personnel managers. The agreement between the external assessments of the same jobs as measured by weighted kappa estimates was reasonably good (kappa $=0.49-0.51)$.

\section{Other measures}

Information on social, demographic, baseline health, and health behaviors were obtained from a self-completed questionnaire at baseline (18). Negative affect was assessed using the negative affect subscale of the affect balance scale (19). Health behavior data included: cigarette smoking ("never smokers", "ex-smokers", and "current smokers"), exercise ( $\geq 1.5$ or $<1.5$ hours of moderate or vigorous exercise per week), alcohol consumption (men who drink $\geq 2$ times/week and have $\geq 20$ units per week and women who drink $\geq 2$ times/ week and have $\geq 10$ units per week as compared to all others), diet (combined frequency of milk, bread, fruit, and vegetable consumption) and body mass index (BMI) $\left(\right.$ BMI $\left.<30, \geq 30 \mathrm{~kg} / \mathrm{m}^{2}\right)$.

\section{Statistical analysis}

For each individual, the numbers of short and long spells of sickness absence were calculated and the length of follow-up was measured in person-years. Rates of sickness absence are expressed per 100 person-years and were standardized using the following age categories: 35-39, 40-44, 45-49 and 50-55 years.

Poisson regression analyses were conducted to determine whether baseline externally assessed work characteristics predicted age-adjusted short- and long-term sickness absence during follow-up. Both self-report and externally assessed measures were divided into tertiles by distribution, ensuring equal variance for both transformed measures.

With respect to each of the three elements of the work environment that we investigated, we created three categories of individuals: (i) those whose external and self-report levels were in the same tertile ("equal"), (ii) those who self-reported a higher level than was assessed for their job externally ("higher self-report") and (iii) those who self-reported a lower frequency than was assessed for their job externally ("higher external report"). We created indicator variables for each of these categories for our analyses. However, when modeling external, self-report, and an interaction term in the same model (table 2), we used these three category variables as continuous in order to have more power to model the interaction. We found no substantial differences in effect estimates by gender in stratified models, so results from combined models are presented (controlling for gender).

Poisson regressions were conducted using Stata 6.0 (Stata Corp, College Station, TX, USA), age standardization was done using R 1.6.2 (20). All other analyses were conducted using SAS version 6.12 for windows (SAS Institute, Cary, NC, USA).

\section{Results}

Table 1 shows the association between externally assessed measures of work characteristics and sickness absence. A lower frequency of conflicting demands, a lower frequency of fast work pace, and lower frequency of decision latitude predict higher rates of short- and long-term sickness absence after controlling for potential confounding variables, although the associations are somewhat attenuated by controlling for civil service grade. Similar results were obtained when job characteristics were assessed through self-report, although they were in general higher for self-reported data (results not shown).

The Pearson correlation between self-report and externally assessed measures was 0.18 for conflicting demands, 0.20 for fast work pace, and 0.34 for decision latitude (all associations were $\mathrm{P}<0.01$ ).

Figure 1 shows age-standardized rates [and 95\% confidence intervals $(95 \% \mathrm{CI})]$ of sickness absence, stratified by tertiles of self-report measurements and externally assessed measurements. This figure allows an examination of how each type (externally or self-assessed) varies within categories of the other. For both conflicting demands and work pace, short- and long-term sickness absence rates are generally more strongly associated with increasing externally measured scores. For decision 
Table 1. Short- and long-term sickness absence predicted by externally assessed work characteristics. Incident rate ratios (IRR) and $95 \%$ confidence intervals ( $95 \% \mathrm{CI}$ ) estimated from Poisson regression. All models include gender.

\begin{tabular}{|c|c|c|c|c|c|c|c|c|c|c|c|c|}
\hline \multirow[b]{3}{*}{$\begin{array}{l}\text { Conflicting } \\
\text { demands }\end{array}$} & \multicolumn{2}{|c|}{ Age $^{a}$} & \multicolumn{2}{|c|}{$\begin{array}{l}\text { Age }{ }^{a} \text { and car and } \\
\text { home ownership }\end{array}$} & \multicolumn{2}{|c|}{$\begin{array}{l}\text { Age a and civil } \\
\text { service grade }\end{array}$} & \multicolumn{2}{|c|}{$\begin{array}{c}\mathrm{Age}^{\mathrm{a}} \text { and } \\
\text { baseline health } \mathrm{c}\end{array}$} & \multicolumn{2}{|c|}{$\begin{array}{c}\mathrm{Age}^{\mathrm{a}} \text { and } \\
\text { health behaviors }\end{array}$} & \multicolumn{2}{|c|}{$\begin{array}{l}\text { Age a car and } \\
\text { home ownership, } \\
\text { grade } \text { b, and } \\
\text { negative affect }\end{array}$} \\
\hline & IRR & $95 \% \mathrm{Cl}$ & IRR & $95 \% \mathrm{Cl}$ & IRR & $95 \% \mathrm{Cl}$ & IRR & $95 \% \mathrm{Cl}$ & IRR & $95 \% \mathrm{Cl}$ & IRR & $95 \% \mathrm{Cl}$ \\
\hline & & & & & & & & & & & & \\
\hline \multicolumn{13}{|c|}{ Short-term } \\
\hline Low & 1.00 & & 1.00 & & 1.00 & & 1.00 & & 1.00 & & 1.00 & \\
\hline Medium & 0.77 & $0.76-0.78$ & 0.78 & $0.77-0.80$ & 0.88 & $0.86-0.89$ & 0.80 & $0.78-0.82$ & 0.79 & $0.77-0.80$ & 0.87 & $0.85-0.89$ \\
\hline High & 0.58 & $0.57-0.59$ & 0.61 & $0.60-0.62$ & 0.75 & $0.73-0.76$ & 0.64 & $0.63-0.66$ & 0.59 & $0.58-0.60$ & 0.76 & $0.75-0.78$ \\
\hline \multicolumn{13}{|c|}{ Long-term } \\
\hline Low & 1.00 & & 1.00 & & 1.00 & & 1.00 & & 1.00 & & 1.00 & \\
\hline Medium & 0.77 & $0.73-0.81$ & 0.79 & $0.75-0.83$ & 0.91 & $0.86-0.95$ & 0.80 & $0.76-0.85$ & 0.81 & $0.77-0.85$ & 0.90 & $0.85-0.96$ \\
\hline High & 0.63 & $0.60-0.66$ & 0.66 & $0.63-0.70$ & 0.83 & $0.78-0.87$ & 0.69 & $0.65-0.73$ & 0.67 & $0-63-0.70$ & 0.85 & $0.80-0.89$ \\
\hline \multicolumn{13}{|l|}{ Work pace } \\
\hline \multicolumn{13}{|c|}{ Short-term } \\
\hline Low & 1.00 & & 1.00 & & 1.00 & & 1.00 & & 1.00 & & 1.00 & \\
\hline Medium & 0.76 & $0.75-0.77$ & 0.78 & $0.77-0.80$ & 0.92 & $0.90-0.94$ & 0.81 & $0.79-0.82$ & 0.78 & $0.77-0.80$ & 0.95 & $0.93-0.97$ \\
\hline High & 0.59 & $0.58-0.60$ & 0.61 & $0.60-0.63$ & 0.75 & $0.73-0.76$ & 0.64 & $0.62-0.65$ & 0.61 & $0.60-0.62$ & 0.75 & $0.74-0.77$ \\
\hline \multicolumn{13}{|c|}{ Long-term } \\
\hline Low & 1.00 & & 1.00 & & 1.00 & & 1.00 & & 1.00 & & 1.00 & \\
\hline Medium & 0.79 & $0.76-0.83$ & 0.83 & $0.79-0.87$ & 0.97 & $0.93-1.03$ & 0.84 & $0.79-0.88$ & 0.84 & $0.80-0.88$ & 1.01 & $0.95-1.07$ \\
\hline High & 0.64 & $0.60-0.67$ & 0.67 & $0.63-0.70$ & 0.81 & $0.76-0.86$ & 0.71 & $0.66-0.75$ & 0.67 & $0.63-0.71$ & 0.85 & $0.80-0.91$ \\
\hline \multicolumn{13}{|l|}{$\begin{array}{l}\text { Decision } \\
\text { latitude }\end{array}$} \\
\hline \multicolumn{13}{|c|}{ Short-term } \\
\hline High & 1.00 & & 1.00 & & 1.00 & & 1.00 & & 1.00 & & 1.00 & \\
\hline Medium & 1.40 & $1.37-1.42$ & 1.38 & $1.35-1.41$ & 1.20 & $1.18-1.23$ & 1.32 & $1.29-1.35$ & 1.39 & $1.36-1.42$ & 1.21 & $1.18-1.23$ \\
\hline Low & 1.90 & $1.86-1.94$ & 1.78 & $1.74-1.82$ & 1.21 & $1.18-1.24$ & 1.71 & $1.68-1.76$ & 1.81 & $1.77-1.85$ & 1.18 & $1.15-1.22$ \\
\hline \multicolumn{13}{|c|}{ Long-term } \\
\hline High & 1.00 & & 1.00 & & 1.00 & & 1.00 & & 1.00 & & 1.00 & \\
\hline Medium & 1.33 & $1.25-1.41$ & 1.31 & $1.24-1.39$ & 1.13 & $1.07-1.20$ & 1.20 & $1.12-1.29$ & 1.32 & $1.24-1.40$ & 1.10 & $1.03-1.18$ \\
\hline Low & 1.91 & $1.81-2.03$ & 1.80 & $1.70-1.91$ & 1.21 & $1.13-1.29$ & 1.66 & $1.55-1.77$ & 1.76 & $1-66-1.87$ & 1.12 & $1.04-1.21$ \\
\hline
\end{tabular}

latitude, however, both subjective and objective measures are associated with short- and long-term sickness absence with approximately equal strength.

Table 2 presents model estimates when both externally and self-assessed measures are included in the same model, along with an interaction term. After adjusting for potential confounding variables, this table shows consistent results with what was illustrated in figure 1 . That is, in mutually adjusted models (ie, both selfand externally assessed measures), externally assessed measures of conflicting demands and fast work pace are more strongly associated with incident rates of sickness absence. Both types of sickness absence are associated with decision latitude, but after adjusting for car and home ownership, civil service grade and negative affect, there is no association. Interaction terms are generally either non-significant or of a very small magnitude, suggesting that within levels of one type of measure (eg, self-assessed), there are no substantial differences in the other (eg, externally assessed).

Individuals who self-report more frequent levels of fast work pace and conflicting demands than were suggested through the external evaluation have significantly higher rates of short-term sickness absence when compared to individuals with higher externally assessed or equal measures (table 3). Higher selfreport frequency of pace also predicts higher rates of long-term sickness absence. The magnitude of association changes little after controlling for possible confounders, although there is some attenuation for higherself report after controlling for civil service grade. A discrepancy between external and self-report of conflicting demands does not consistently predict higher rates of long-term sickness absence. Discrepancies 

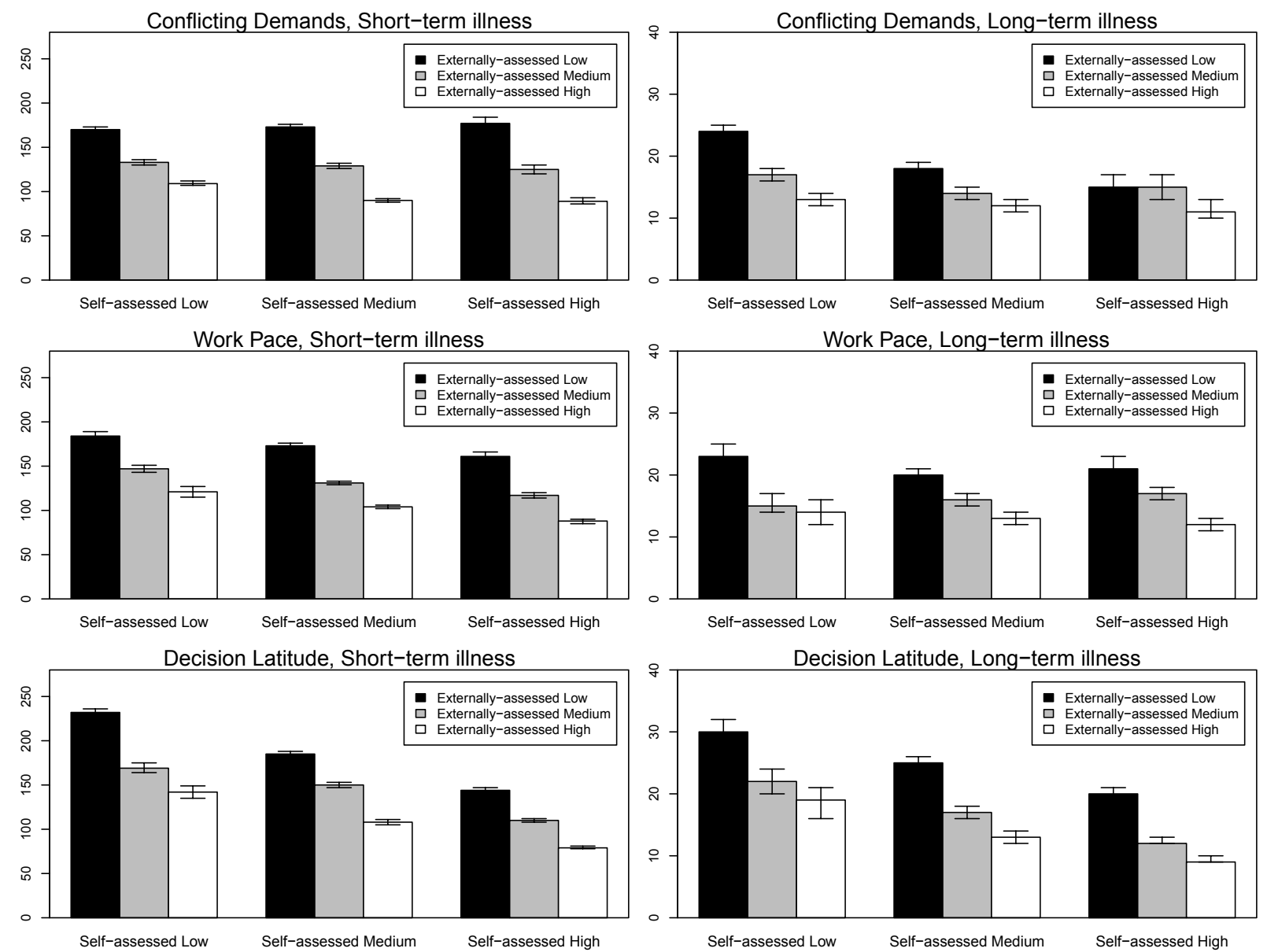

Figure 1. Age-standardized rates of sickness absence per 100 person-years, comparing external assessment and self-report measures, $95 \%$ confidence interval shown as vertical lines.

in measures of decision latitude have only a slight or non-significant effect on predicting short- or long-term sickness absence.

\section{Discussion}

The aim of this study was to explore the relationship between two different methods of measuring the psychosocial work environment (self-report and external assessment) and assess whether discrepancies between these measurements were correlated with long- and short-term sickness absence. We found that on their own, both externally assessed and self-reported high frequency of conflicting demands, fast work pace and high job discretion were all associated with decreased long- and short-term sickness absence. We found that in regression models adjusted simultaneously for selfand externally assessed workplace measures, the latter measures were more strongly associated than self-report measures with sickness absence for frequency of conflicting demands and fast work pace. Our results also show that individuals who self-report higher levels of pace and conflicting demands than were suggested through the external evaluation (ie, higher self-report) had higher rates of short-term sickness absence, and for work pace also higher rates of long-term sickness absence, although this affect was somewhat attenuated after controlling for civil service grade.

The main effect results (table 1) were similar in direction and magnitude to earlier investigations of the Whitehall II cohort $(8,9)$ and results from other white-collar populations. The association of high fast work pace and high conflicting demands with less sickness absence may be due to the fact that this is a white-collar population and these work characteristics may be associated with a detrimental "passive" work environment $(2,8,9)$. A further possibility is that there is more pressure to be present at work for individuals 
Table 2. Short- and long-term sickness absence: Incident rate ratios (IRR) and 95\% confidence intervals (95\% CI) from models containing both external and self-report measures and an interaction term. All models include gender.

\begin{tabular}{|c|c|c|c|c|c|c|c|c|c|c|c|c|}
\hline & \multicolumn{6}{|c|}{$\begin{array}{l}\text { Age a, external measure, self-report measure, } \\
\text { external-self-report interaction }\end{array}$} & \multicolumn{6}{|c|}{$\begin{array}{l}\text { Age a, external measure, self-report measure, } \\
\text { external-self-report interaction, car and home ownership, } \\
\text { civil service grade }{ }^{b} \text {, negative affect }\end{array}$} \\
\hline & \multicolumn{2}{|c|}{ External } & \multicolumn{2}{|c|}{ Self-report } & \multicolumn{2}{|c|}{$\begin{array}{l}\text { External-self- } \\
\text { report interaction }\end{array}$} & \multicolumn{2}{|c|}{ External } & \multicolumn{2}{|c|}{ Self-report } & \multicolumn{2}{|c|}{$\begin{array}{l}\text { External-self- } \\
\text { report interaction }\end{array}$} \\
\hline & IRR & $95 \% \mathrm{Cl}$ & IRR & $95 \% \mathrm{Cl}$ & IRR & $95 \% \mathrm{Cl}$ & IRR & $95 \% \mathrm{Cl}$ & IRR & $95 \% \mathrm{Cl}$ & IRR & $95 \% \mathrm{Cl}$ \\
\hline \multicolumn{13}{|l|}{$\begin{array}{l}\text { Conflicting } \\
\text { demands }\end{array}$} \\
\hline Short-term & 0.79 & $0.78-0.80$ & 1.02 & $1.01-1.04$ & 0.93 & $0.92-0.95$ & 0.93 & $0.92-0.95$ & 1.15 & $1.13-1.17$ & 0.93 & $0.92-0.94$ \\
\hline Long-term & 0.73 & $0.70-0.76$ & 0.76 & $0.73-0.81$ & 1.12 & $1.08-1.17$ & 0.90 & $0.86-0.94$ & 0.90 & $0.85-0.95$ & 1.10 & $1.05-1.15$ \\
\hline \multicolumn{13}{|l|}{ Work pace } \\
\hline Short-term & 0.81 & $0.79-0.83$ & 0.93 & $0.92-0.95$ & 0.95 & $0.94-0.97$ & 0.91 & $0.89-093$ & 0.98 & $0.96-1.00$ & 0.98 & $0.96-0.99$ \\
\hline Long-term & 0.78 & $0.74-0.82$ & 0.97 & $0.93-1.01$ & 0.99 & $0.96-1.04$ & 0.90 & $0.85-0.96$ & 1.05 & $1.00-1.12$ & 1.04 & $0.99-1.09$ \\
\hline \multicolumn{13}{|l|}{$\begin{array}{l}\text { Decision } \\
\text { latitude }\end{array}$} \\
\hline Short-term & 0.78 & $0.77-0.80$ & 0.80 & $0.79-0.81$ & 0.97 & $0.96-0.98$ & 0.96 & $0.94-0.98$ & 0.97 & $0.96-0.99$ & 0.98 & $0.97-1.00$ \\
\hline Long-term & 0.77 & $0.73-0.81$ & 0.81 & $0.78-0.83$ & 0.94 & $0.90-0.97$ & 1.00 & $0.94-1.07$ & 1.04 & $1.00-1.09$ & 0.95 & $0.92-0.99$ \\
\hline
\end{tabular}

a Categories of age are $35-39,40-44,45-49,50-55$ years at baseline;

${ }^{\circ}$ Civil service grade includes six levels.

in jobs where there are more frequent conflicting demands and more often a fast work pace - that these individuals have higher levels of "sickness presenteeism" (ie, being at work when sick) (21).

The results for mutually adjusted models (table 2) generally confirm the descriptive presentation shown in the figure - that for both of the demand variables, external evaluation was associated with greater differences in sickness absence than the self-report measures. The most direct interpretation of this finding is that objective characteristics of the job, those not part of the subject's perception or evaluation, matter most for sickness absence. As we described in the results section, the correlation between externally and self-assessed decision latitude was much higher than for the other measures, thus each measure did not provide as much unique information, in part likely due to this question involving less individual interpretation (11).

There are three potential explanations for the significant association of discrepancies between self- and externally assessed measures of conflicting demands and fast work pace (but not decision latitude) with short- and long-term sickness absence (table 3). First, these associations may be due to residual confounding by socioeconomic status. However, this is unlikely because estimates of association do not change substantially after controlling for three measures of socioeconomic status. A second explanation is that discrepancy represents the difference between how people actually do their jobs and how the job is structured. For example, if an individual frequently works at a more rapid pace than is typically required of that job, that individual would be classified as higher self-report for job pace. This higher pace could be because of choice of the individual or due to pressure from supervisors to work at a faster pace, and either of these may result in more sickness absence. Third, individuals who have a perception of more conflicting demands or having to work at a more rapid work pace, beyond the externally assessed level, may be at risk for increased sickness absence. This last possibility implies that discrepancy indicates a characteristic of the individual that may relate to sickness absence. It is unlikely, however, that this is strongly related to negative affect because controlling for this does not meaningfully change estimates of association. A contrast in our findings is that while there is a positive association between higher self-reported fast pace and conflicting demands and sickness absence (table 3), there is a negative association with the main effects (table 1). That is, higher levels of the main effects are associated with lower levels of sickness absence, while self-reporting relatively higher levels results in more frequent sickness absence. One possible reason for this is that actual demands above a certain level of job structure may be hazardous to mental or physical health. Alternatively, the discrepancy may capture a lack of "person-environment fit", a theory that posits work demands must be matched with an individual's ability to meet these demands (22). The effects of measurement methods of the work environment and discrepancies have not been previously examined with respect to sickness absence, but several studies have examined this in relation to blood pressure. Greiner et al (23) found that among bus drivers, individuals who had low self-reported levels yet higher externally measured levels of stress had the highest levels of blood pressure. Netterstrøm \& Suadicani (24) found that bus drivers 
Table 3. Short- and long-term sickness absence: Incident rate ratios (IRR) and 95\% confidence intervals (95\% CI) for individuals with higher self-report versus equal measures and higher external report versus equal measures. All models include gender..

\begin{tabular}{|c|c|c|c|c|c|c|c|c|c|c|c|c|}
\hline & \multicolumn{2}{|c|}{ Age $^{a}$} & \multicolumn{2}{|c|}{$\begin{array}{l}\text { Age a and car and } \\
\text { home owner }\end{array}$} & \multicolumn{2}{|c|}{$\begin{array}{l}\text { Age a and civil } \\
\text { service grade }\end{array}$} & \multicolumn{2}{|c|}{$\begin{array}{l}\text { Age a and baseline } \\
\text { health }{ }^{c}\end{array}$} & \multicolumn{2}{|c|}{$\begin{array}{l}\text { Age a and health } \\
\text { behaviors }{ }^{d}\end{array}$} & \multicolumn{2}{|c|}{$\begin{array}{c}\text { Age a, car and } \\
\text { home ownership, } \\
\text { civil service } \\
\text { grade }{ }^{b} \text { and } \\
\text { negative affect }\end{array}$} \\
\hline & IRR & $95 \% \mathrm{Cl}$ & IRR & $95 \% \mathrm{Cl}$ & IRR & $95 \% \mathrm{Cl}$ & IRR & $95 \% \mathrm{Cl}$ & IRR & $95 \% \mathrm{Cl}$ & IRR & $95 \% \mathrm{Cl}$ \\
\hline \multicolumn{13}{|l|}{ Conflicting demands } \\
\hline \multicolumn{13}{|l|}{ Short-term } \\
\hline $\begin{array}{l}\text { Higher self-report } \\
\text { Equal }\end{array}$ & $\begin{array}{l}1.15 \\
1.00\end{array}$ & $1.13-1.18$ & $\begin{array}{l}1.19 \\
1.00\end{array}$ & $1.16-1.21$ & $\begin{array}{l}1.17 \\
1.00\end{array}$ & $1.15-1.20$ & $\begin{array}{l}1.16 \\
1.00\end{array}$ & $1.13-1.18$ & $\begin{array}{l}1.17 \\
1.00\end{array}$ & $1.14-1.19$ & $\begin{array}{l}1.14 \\
1.00\end{array}$ & $1.11-1.16$ \\
\hline $\begin{array}{l}\text { Higher external } \\
\text { report }\end{array}$ & 0.77 & $0.76-0.79$ & 0.81 & $0.79-0.82$ & 0.86 & $0.85-0.88$ & 0.82 & $0.80-0.83$ & 0.78 & $0.77-0.80$ & 0.80 & $0.79-0.82$ \\
\hline \multicolumn{13}{|l|}{ Long-term } \\
\hline $\begin{array}{l}\text { Higher self-report } \\
\text { Equal }\end{array}$ & $\begin{array}{l}0.90 \\
1.00\end{array}$ & $0.85-0.96$ & $\begin{array}{l}0.95 \\
1.00\end{array}$ & $0.89-1.02$ & $\begin{array}{l}0.92 \\
1.00\end{array}$ & $0.87-0.98$ & $\begin{array}{l}0.94 \\
1.00\end{array}$ & $0.87-1.01$ & $\begin{array}{l}0.92 \\
1.00\end{array}$ & $0.86-0.98$ & $\begin{array}{l}0.92 \\
1.00\end{array}$ & $0.85-0.98$ \\
\hline $\begin{array}{l}\text { Higher external } \\
\text { report }\end{array}$ & 0.76 & $0.73-0.80$ & 0.82 & $0.84-0.92$ & 0.88 & $0.84-0.92$ & 0.83 & $0.78-0.88$ & 0.79 & $0.75-0.83$ & 0.80 & $0.75-0.85$ \\
\hline \multicolumn{13}{|l|}{ Work pace } \\
\hline \multicolumn{13}{|l|}{ Short-term } \\
\hline Higher self-report & 1.19 & $1.17-1.21$ & 1.16 & $1.14-1.18$ & 1.08 & $1.06-1.10$ & 1.10 & $1.08-1.13$ & 1.17 & $1.14-1.19$ & 1.13 & $1.11-1.15$ \\
\hline Equal & 1.00 & & 1.00 & & 1.00 & & 1.00 & & 1.00 & & 1.00 & \\
\hline $\begin{array}{l}\text { Higher external } \\
\text { report }\end{array}$ & 0.91 & $0.89-0.92$ & 0.92 & $0.90-0.94$ & 0.92 & $0.91-094$ & 0.89 & $0.87-0.90$ & 0.79 & $0.77-0.80$ & 0.89 & $0.88-0.91$ \\
\hline \multicolumn{13}{|l|}{ Long-term } \\
\hline $\begin{array}{l}\text { Higher self-report } \\
\text { Equal }\end{array}$ & $\begin{array}{l}1.18 \\
1.00\end{array}$ & $1.13-1.24$ & $\begin{array}{l}1.16 \\
1.00\end{array}$ & $1.10-1.21$ & $\begin{array}{l}1.06 \\
1.00\end{array}$ & $1.01-1.11$ & $\begin{array}{l}1.10 \\
1.00\end{array}$ & $1.04-1.16$ & $\begin{array}{l}0.92 \\
1.00\end{array}$ & $0.86-0.98$ & $\begin{array}{l}1.12 \\
1.00\end{array}$ & $1.06-1.18$ \\
\hline $\begin{array}{l}\text { Higher } \\
\text { external-report }\end{array}$ & 0.85 & $0.80-0.90$ & 0.87 & $0.82-0.92$ & 0.87 & $0.83-0.92$ & 0.84 & $0.79-0.90$ & 0.79 & $0.75-0.83$ & 0.85 & $0.80-0.90$ \\
\hline \multicolumn{13}{|l|}{ Decision latitude } \\
\hline \multicolumn{13}{|l|}{ Short-term } \\
\hline Higher self-report & 1.04 & $1.03-1.06$ & 1.03 & $1.01-1.05$ & 0.99 & $0.97-1.00$ & 1.03 & $1.01-1.05$ & 1.04 & $1.02-1.05$ & 1.02 & $1.00-1.04$ \\
\hline Equal & 1.00 & & 1.00 & & 1.00 & & 1.00 & & 1.00 & & 1.00 & \\
\hline $\begin{array}{l}\text { Higher external } \\
\text { report }\end{array}$ & 1.00 & $0.98-1.02$ & 0.99 & $0.97-1.01$ & 0.94 & $0.92-0.96$ & 0.99 & $0.97-1.02$ & 1.02 & $0.99-1.04$ & 1.00 & $0.98-1.03$ \\
\hline \multicolumn{13}{|l|}{ Long-term } \\
\hline Higher self-report & 1.10 & $1.05-1.15$ & 1.09 & $1.04-1.13$ & 1.03 & $0.99-1.08$ & 1.09 & $1.03-1.15$ & 1.10 & $1.05-1.16$ & 1.09 & $1.03-1.15$ \\
\hline Equal & 1.00 & & 1.00 & & 1.00 & & 1.00 & & 1.00 & & 1.00 & \\
\hline $\begin{array}{l}\text { Higher external } \\
\text { report }\end{array}$ & 1.06 & $1.00-1.13$ & 1.07 & $0.93-1.05$ & 0.99 & $0.93-1.05$ & 1.00 & $0.97-1.08$ & 1.07 & $1.00-1.14$ & 1.02 & $0.95-1.10$ \\
\hline
\end{tabular}

a Categories of age are 35-39, 40-44, 45-49, 50-55 years at baseline;

${ }^{\mathrm{b}}$ Civil service grade includes six levels.

c Baseline health includes long-term illness, diabetes and self-rated health over the past year.

${ }^{\mathrm{d}}$ Health behaviors includes exercise, smoking, diet, alcohol and body mass index.

who worked in high traffic intensity - yet had high job satisfaction - had an increased risk of ischemic heart disease as compared to those working in the same environment but with a low degree of job satisfaction. These contrasts with our findings may be due to: (i) the different outcomes examined (sickness absence versus blood pressure), (ii) the different populations (office workers versus bus drivers), or (iii) the different measures of stress exposures measured. Future work is needed to understand which of these reasons is most relevant for our divergent findings.

There are several strengths in using the Whitehall II cohort to address our questions. The external evaluations were performed without reference to a specific individual, but were still specific to that individual's job. This provides greater specificity than inferred measures such as job matrixes. This cohort also had records of both long- and short-term sickness absence. Short-term sickness absence may be regarded as a coping behavior in reaction to sickness, symptoms, and work and life stresses (21), reflecting an individual's perception of her/his own health. In contrast, long-term sickness absence is medically certified and thus more indicative of a medically recognized disease. While long-term sickness absence is not always associated with physical pathology (22), other investigations in this cohort 
have shown that long-term sickness absence is strongly associated with mortality (23).

This study also has several limitations. For the purposes of this study only three questions that were similar between external and self-report were available for analysis $(8,9)$. Additional questions assessing each construct of workplace environment would likely lead to less measurement error and less bias of our results toward null associations. External measurements assessed the actual job, not the individual working, as is the case with the direct observation method of workers that is often used (25). External observer ratings have several limitations: (i) limited time of observation, (ii) inobservability of mental processes and (iii) effects of observation on work behavior (11), of which only the second applies to the supervisor ratings used in this study. However, a further disadvantage of supervisor ratings is that it may be a less precise measurement of an individual's work environment since the individual him- or herself was never observed. Supporting this possibility is the fact that the kappas of agreement of external reviewers are only moderate. A study of blue-collar mill workers indicates that experienced fellow workers may provide more reliable estimates of the psychosocial work conditions (25). External environment evaluators may also have had their own specific biases. External measurements were taken only at baseline, although we used up to 13 years of follow-up sickness absence data. This would most likely result in a bias towards the null if the structure of jobs changed for study participants. Although we used both job grade and car and home ownership to control for confounding by social class, the possibility of residual confounding remains. There has also been sample attrition in the Whitehall II cohort, and follow-up is less likely for older and lower job level participants, however analyses conducted with 7 years of follow-up time were similar (results not shown). Other limitations of our findings are the ceiling and floor effects present when calculating discrepancies.

There are a number of ways in which future work could differentiate between the interpretations of the meaning of discrepancy between self-rated and objective measures. First, studies should investigate discrepancy in relation to more objective health outcomes such as biomarkers or physician-diagnosed disease or even death. Future studies of the work environment may also benefit from self-report questions that are less influenced by individual perceptions (26) and utilize novel methods for incorporating multiple sources of observation (27) that ensures an accurate capture of the actual circumstances of the structured working conditions. It may also be useful to consider how discrepancy between types of measures depends on categories of interaction between demand and control aspects of the work environment (eg, individuals in "passive" jobs) $(1,5)$. In addition, the exploration of alternative causal structures - for example that discrepancy as a construct is not independent of objective and subjective measures - is important for ensuring that our results are not due to confounding. Only with such advances will we be able to differentiate between individual and structural explanations for the association of work characteristics with health outcomes.

\section{Acknowledgements}

The Whitehall II study has been supported by grants from the Medical Research Council; the British Heart Foundation; the UK Health and Safety Executive; the UK Department of Health; the US National Institutes of Health National Heart Lung and Blood Institute (HL36310) and the National Institute on Aging (AG13196); the Agency for Health Care Policy Research (HS06516); and the John D and Catherine T MacArthur Foundation Research Networks on Successful Midlife Development and Socio-economic Status and Health. M Marmot is supported by an Medical Research Council Research Professorship.

We also thank all participating civil service departments and their welfare, personnel, and establishment officers; the Occupational Health and Safety Agency; the Council of Civil Service Unions; all participating civil servants in the Whitehall II study; Paul Clarke, Jennifer Head, Martin Shipley and all other members of the Whitehall II study team. None of the authors have financial or affiliation interests that may cause a financial conflict of interest.

\section{References}

1. Karasek PA, Theorell T. Healthy work: stress, productivity, and the reconstruction of working life. New York (NY): Basic Books; 1990.

2. Marmot MG, Siegrist J, Theorell T. Health and the psychosocial environment at work. In: Marmot MG, Wilkinson RG, editors. Social determinants of health. 2nd ed. Oxford (UK): Oxford University Press; 2006. p 267-96.

3. Bobak M, Hertzman C, Skodova Z, Marmot MG. Association between psychosocial factors at work and nonfatal myocardial infarction in a population-based case-control study in Czech men. Epidemiology. 1998;9(1):43-7.

4. Bosma H, Marmot MG, Hemingway H, Nicholson AC, Brunner E, Stansfeld S. Low job control and risk of coronary heart disease in Whitehall II (prospective cohort) study. BMJ. 1997;314:558-65. 
5. Karasek PA. Job demands, job decision latitude, and mental strain: implications for job redesign. Admin Sci Q. 1979;24:285-307.

6. Kohn M, Schooler C. Occupational experience and psychological functioning: an assessment of reciprocal effects. Am Sociolog Rev. 1973;38:97-118.

7. Marmot MG, Bosma H, Hemingway H, Brunner E, Stansfeld S. Contribution of job control and other risk factors to social variations in coronary heart disease incidence. Lancet. 1997;350:235-9.

8. North F, Syme SL, Feeney A, Head J, Shipley MJ, Marmot MG. Explaining socioeconomic differences in sickness absence: the Whitehall II study. BMJ. 1993;86:361-6.

9. North FM, Syme SL, Feeney A, Shipley M, Marmot M. Psychosocial work environment and sickness absence among British civil servants: the Whitehall II Study. Am J Public Health. 1996;86:332-40.

10. Theorell T, Karasek RA. Current issues relating to psychosocial job strain and cardiovascular disease research. J Occup Health Psychol. 1996;1(1):9-26.

11. Frese M, Zapf D. Methodlogical issues in the study of work stress: objective vs. subjective measurement of work stress and the question of longitudinal studies. In: Cooper C, Payne $\mathrm{R}$, editors. Causes, coping, and consequences of stress at work. New York (NY): John Wiley \& Sons Ltd; 1988. p 375-411.

12. Hammar N, Alfredsson L, Johnson JV. Job strain, social support at work, and incidence of myocardial infarction. Occup Environ Med. 1998;55:548-53.

13. Sacker A, Bartley M, Firth D, Fitzpatrick R, Marmot MG. The relationship between job strain and coronary heart disease: evidence from an English sample of the working male population. Psychol Med. 2001;31(2):279-90.

14. Kristensen TS. Job stress and cardiovascular disease: a theoretic critical review. J Occup Health Psychol. 1996;1:246-60.

15. Landsbergis P, Theorell T, Schwartz J, Greiner BA, Krause N. Measurement of psychosocial workplace exposure variables. Occup Med. 2000;15:163-88.

16. Kasl S. Methodologies in stress and health: past difficulties, present dilemmas, future directions. In: Kasl S, Copper C, editors. Research methods in stress and health psychology. New York (NY): John Wiley \& Sons, Ltd; 1987. p 307-18.
17. Semmer N, Zapf D, Greif S. 'Shared job strain': a new approach for assessing the validity of job stress measurements. J Occup Organ Psychol. 1996;69:293-310.

18. Marmot M, Davey Smith G, Stansfeld S, Patel C, North F, Head J, et al. Health inequalities among British civil servants: the Whitehall II study. Lancet. 1991;337:1387-93.

19. Bradburn NM. The structure of psychological well being. Chicago (IL): Aldine; 1969.

20. R-Development-Core-Team. R: a language and environment for statistical computing. Vienna: R Foundation for Statistical Computing; 2008.

21. Aronsson G, Gustafsson K, Dallner M. Sick but yet at work. an empirical study of sickness presenteeism. J Epidemiol Community Health. 2000;54(7):502-9.

22. Caplan RD, Cobb S, French JRP, Van Harrison R, Pinneau SR. Job demands and worker health. Cincinnati $(\mathrm{OH})$ : National Institute for Occupational Safety and Health; 1975. Publication no $75-168$.

23. Greiner BA, Krause N, Ragland DR, Fisher JM. Occupational stressors and hypertension: a multi-method study using observer-based job analysis and self-reports in urban transit operators. Soc Sci Med. 2004;59:1081-94.

24. Netterstrøm B, Suadicani P. Self-assessed job satisfaction and ischaemic heart disease mortality: a 10-year follow-up of urban bus drivers. Int J Epidemiol. 1993;22:51-6.

25. Ostry AS, Marion SA, Demers PA, Hershler R, Kelly S, Teschke K, et al. Comparison of expert-rater methods for assessing psychosocial job strain. Scand J Work Environ Health. 2001;27(1):70-5.

26. Spector PE, Fox S. Reducing subjectivity in the assessment of the job environment: development of the Factual Autonomy Scale (FAS). J Organ Behav. 2003;24:417-32.

27. Horton NJ, Laird NM, Murphy JM, Monson RR, Sobol AM, Leighton AH. Multiple informants: mortality associated with psychiatric disorders in the Stirling County Study. Am J Epidemiol. 2001;2001:649-50.

Received for publication: 30 November 2009 